\title{
EXPERIMENTAL INVESTIGATION OF DOUBLE-PIPE HEAT EXCHANGER WITH HELICAL FINS ON THE INNER ROTATING TUBE
}

\author{
Shewale Omkar $\mathbf{M}^{\mathbf{1}}$, Mane Pravin A ${ }^{\mathbf{2}}$, Gazge Sajid A Hameed ${ }^{\mathbf{3}}$, Pasanna Pradeep A ${ }^{\mathbf{4}}$ \\ ${ }^{1}$ Student, Department of Mechanical Engineering, WCE, Sangli, Maharashtra, India 416415 \\ ${ }^{2}$ Assistant Professor, Department of Mechanical Engineering, WCE, Sangli, Maharashtra, India 416415 \\ ${ }^{3}$ Student, Department of Mechanical Engineering, WCE, Sangli, Maharashtra, India 416415 \\ ${ }^{4}$ Student, Department of Mechanical Engineering, WCE, Sangli, Maharashtra, India 416415
}

\begin{abstract}
Heat exchanger is an important device in all the thermal systems. The heat exchanger is widely used equipment in different industries such as process, petroleum refining, chemicals and paper etc. Energy and material saving considerations as well as environmental challenges in the industry have stimulated the demand for high efficiency heat exchanger. To improve the efficiency of heat exchanger one must think of heat transfer enhancement in heat exchanger. Moreover heat transfer enhancement enables the size of heat exchanger to be considerably decreased. A high rate of heat transfer with minimum space requirement is necessity for compact heat exchanger. In present work, to improve the heat transfer characteristic of the double pipe heat exchanger, the helical fins were installed on the outer surface of the inner tube and the level of turbulence increased by the rotating the inner tube. The length of heat exchanger was $1 \mathrm{~m}$ and the pitch of helical fins kept constant equal to $17 \mathrm{~mm}$. The convective heat transfer coefficients were obtained for the stationary as well as rotating inner tube for the counter flow mode using water as cold fluid in the tube side and glycerol as hot fluid in the shell side. The flow rate of cold fluid was kept constant and that of hot fluid was varied. The Nusselt number was calculated for the each speed of the rotation and compared with standard values obtained from Dittus-Boelter equation. The helical fins increases heat transfer area and rotation of the inner tube increases the mixing of fluid particles which is necessary for the convection mode of heat transfer. The Nusselt number increased up to $64 \%$ at 100 rpm compared to stationary inner tube with helical fins.
\end{abstract}

Keywords: Double pipe heat exchanger, Helical fins, Rotating inner tube, Nusselt number

\section{INTRODUCTION}

The heat exchanger is a device used to transfer the heat from the hot fluid to cold fluid with maximum rate and minimum investment. The heat exchanger is an important device in various thermal systems for e.g. condenser and evaporator in refrigeration systems, boiler \& condenser in steam power plants etc. The heat exchanger has wide variety of industrial applications such as process industries, chemical industries, food industries etc. Now there is need of the compact heat exchangers to give required heat transfer rate with minimum space requirement. The helical fins on the inner tube increase the area available for the heat transfer and the rotation of inner tube increases the turbulence. With helical fins at larger pitch, the efficiency of the heat transfer enhancement however is rather low when the total length of heat exchanger is fixed. At high Reynolds number, pressure drop will increase sharply if the helical pitch decreases. Due to this reason the heat transfer enhancement with helical fins is more suitable at low Reynolds number [1]. Li Zhang et al. [1] experimentally investigated the heat transfer characteristics of the double pipe heat exchanger with helical fins and vortex generators. Heat transfer characteristics were studied with air as working fluid and steam as heating medium. In their chosen geometry, the heat transferred by the heat exchangers enhanced by the helical fins and the vortex generators of delta- wing type was 87$115 \%$ more than that transferred by the heat exchanger with smooth inner tube. W. El-Maghlany et al. [2] studied the fluid flow and heat transfer characteristics of double-pipe heat exchanger with rotating inner tube. The experiments carried out for the speed of rotation of inner tube from 0 to $1000 \mathrm{rpm}$. The effectiveness and NTU number obtained for parallel flow and counter flow arrangement. They found that speed of rotation increases the Reynolds number, NTU and effectiveness values. Zhengguo Zhang et al. [3] were made attempts to investigate the heat transfer characteristics of a helically baffled heat exchanger combined with one threedimensional finned tube. For the counter mode operation the experiments were carried out and overall heat transfer coefficient determined using modified Wilson-plot. The agreement with the numerical and experimental predictions of Nusselt number and pressure drop values were well within $6.3 \%$ for Nusselt number and $9.8 \%$ for pressure drop in the shell side, respectively. Haifa El-Sadi et al. [4] presented experimental and numerical simulation of a micro screw heat exchanger to determine the overall heat transfer coefficient. M.R.H. Nobari and K. Gharali [5] numerically studied the effect of internal fins on laminar fluid flow and heat transfer characteristics inside rotating straight pipe and 
stationary curved pipes. They found that at the optimum value of fin height for the Dean number less than 100, heat transfer rate is maximum and heat transfer coefficient is 6 times higher than that of plain inner tube. Pravin Mane et al. [6] performed numerical analysis of pulse tube cryocooler. This simulation gives the variation in temperature and pressure with respect to time at the cold heat exchanger. The present study aims to experimentally investigate heat transfer characteristics of double pipe heat exchanger with helical fins on the outer surface of inner rotating tube. The comparison of Nusselt number is performed between the experimental results and theoretical values obtained from standard Dittus-Boelter equation.

\section{EXPERIMENTAL PROCEDURE}

Fig-1 is the schematic layout of experimental set-up, which is used to obtain heat transfer rate and pressure drop. The set-up consists of double pipe heat exchanger with helical fins on the outer surface of inner tube. The length of the inner tube is $1 \mathrm{~m}$ and the fins provided on it for $970 \mathrm{~mm}$ length. Fig-2 is the inner tube with helical fins on outer surface. The height, thickness and pitch of the fins are 16 $\mathrm{mm}, 1 \mathrm{~mm}$ and $17 \mathrm{~mm}$ respectively. To secure the helical on the outer surface of the inner tube, spiral fining machine is used.

There are two separate loops. The hot fluid glycerol is flowing through the upper loop shown in Fig-1. The glycerol is flowing through the shell side of the heat exchanger whose temperature is maintained by the adjustment of heater and flow rate is controlled by the adjustment of the by-pass valve and gear pump. The lower loop is to circulate the cold water on the tube side with constant inlet temperature. The water flow rate is controlled by bypass valve and centrifugal pump. The heat exchanger is operated in counter flow mode.

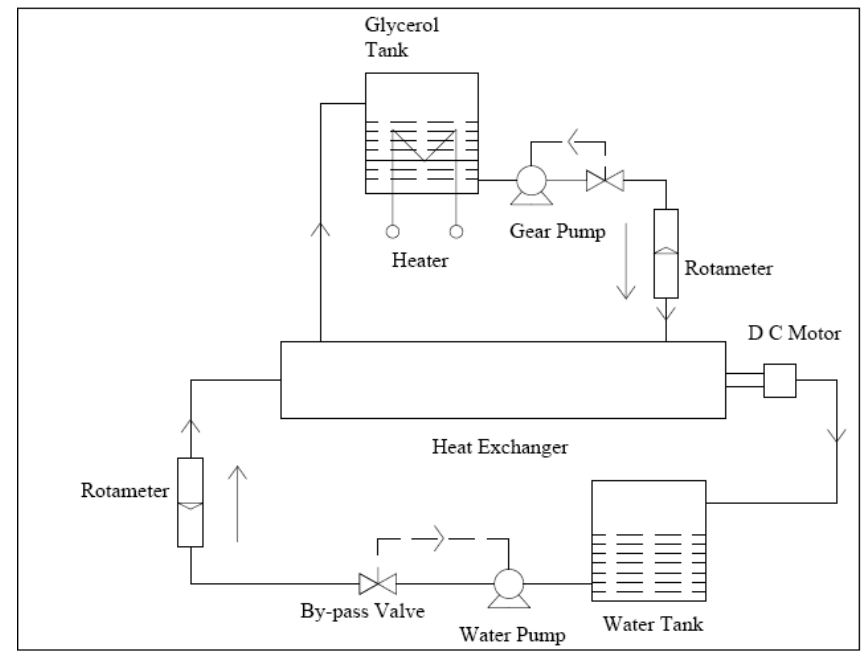

Fig -1: Schematic of experimental set-up

The calibrated K- type thermocouples are used to measure the inlet and outlet temperatures of the glycerol and water. To locate the thermocouples holes of $0.5 \mathrm{~mm}$ are drilled at required position and thermocouples with $0.3 \mathrm{~mm}$ diameter inserted into holes and fixed. The pressure drop is measured for the shell side fluid i.e. glycerol using pressure manometer. The water flow rate is maintained constant at $750 \mathrm{LPH}$. The glycerol flow rate is varied from the $200 \mathrm{LPH}$ to $400 \mathrm{LPH}$. The rotation is provided for the inner tube with help of DC motor and the speed of rotation is varied from the $0 \mathrm{rpm}$ to $100 \mathrm{rpm}$. The inlet and outlet temperatures are recorded for the hot and cold fluids for 0, 50 and $100 \mathrm{rpm}$ for the above mentioned flow rates. The outer surface of heat exchanger is insulated by the rubber. The temperature measurements enabled studying the effect of different flow parameters such as Reynolds number, Prandtl number as well as heat transfer characteristics of double pipe heat exchanger with helical fins on the outer surface of inner rotating tube. The Nusselt number and heat transfer coefficient are obtained for each observation.

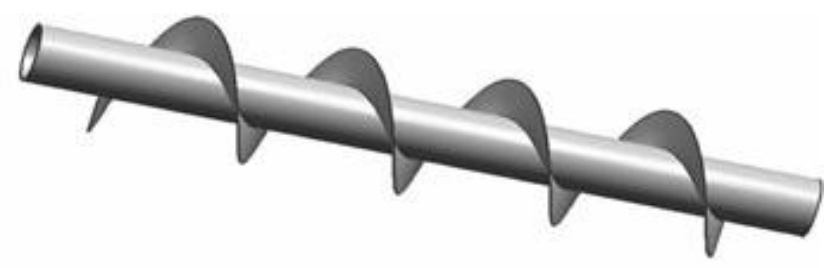

Fig -2: Inner tube with helical fins on outer surface [1]

\section{DATA REDUCTION}

To study the heat transfer characteristics of double pipe heat exchanger with helical fins on the outer surface of rotating inner tube, the shell side heat transfer coefficient $h_{o}$ must be determined.

Heat rejected by hot fluid i.e. glycerol is

$$
\begin{aligned}
& \mathrm{Q}_{\text {glycerol }}=\dot{\mathrm{m}}_{\text {glycerol }} \mathrm{XC}_{\mathrm{p} \text { glycerol }} \mathrm{X}\left(\mathrm{T}_{\text {glycerol in }}-\right. \\
& \mathrm{T}_{\text {glycerol out }} \text { ) }
\end{aligned}
$$

Heat absorbed by cold fluid i.e. water is

$$
\mathrm{Q}_{\text {wate } \mathrm{r}}=\dot{\mathrm{m}}_{\text {water }} \times \mathrm{C}_{\mathrm{p} \text { water }} \times\left(\mathrm{T}_{\text {water out }}-\mathrm{T}_{\text {water in }}\right)
$$

Average heat transfer rate is given by

$$
\mathrm{Q}_{\mathrm{avg}}=\frac{\mathrm{Q}_{\text {glycerol }}+\mathrm{Q}_{\mathrm{water}}}{2}
$$

The thermodynamic and transport properties of glycerol and water are calculated at the bulk mean temperature of respected fluids.

$$
\mathrm{T}_{\text {mean bulk }}=\frac{\mathrm{T}_{\text {bulk inlet }}+\mathrm{T}_{\text {bulk outlet }}}{2}
$$

$\mathrm{T}_{\text {mean bulk }} \quad=$ Bulk mean temperature

$\mathrm{T}_{\text {bulk inlet }} \quad=$ Bulk mean temperature at inlet

$\mathrm{T}_{\text {bulk outlet }}=$ Bulk mean temperature at outlet

The average heat transfer is also given by

$$
\mathrm{Q}_{\mathrm{avg}}=\mathrm{U} \times \mathrm{A} \times \mathrm{LMTD}
$$


The overall heat transfer coefficient (U) based on outer surface area of inner tube is

$$
\mathrm{U}=\frac{\mathrm{Q}_{\mathrm{avg}}}{\mathrm{A}_{\mathrm{o}} \mathrm{LMTD}}
$$

$A_{o}$ is the heat transfer area considering the outer surface area of inner tube and total surface area of fins and LMTD is log mean temperature difference.

Log mean temperature difference (LMTD) is given as

$$
\begin{aligned}
& \text { LMTD }=\frac{\theta_{1}-\theta_{2}}{\ln \frac{\theta_{1}}{\theta_{2}}} \\
& \theta_{1}=\mathrm{T}_{\text {glycerol in }}-\mathrm{T}_{\text {water out }} \\
& \theta_{2}=\mathrm{T}_{\text {glycerol out }}-\mathrm{T}_{\text {water in }} \\
& \mathrm{A}_{\mathrm{o}}=\pi \mathrm{d}_{\mathrm{o}} \mathrm{l}+\mathrm{A}_{\mathrm{f}}
\end{aligned}
$$

Where $A_{f}=$ surface area of helical fins.

$$
\mathrm{A}_{\mathrm{f}}=\mathrm{n} \times \mathrm{A}_{\text {fin }}
$$

Where $A_{\text {fin }}$ is surface area of single fin considering fin having circular cross-section.

Number of fins, $\quad \mathrm{n}=\frac{1}{\mathrm{p}}$

Where $\mathrm{l}$ is total length of fins and $\mathrm{p}$ is the pitch of single fin

$$
\begin{aligned}
& A_{\text {fin }}=A_{(c / s) \text { of fin }}-A_{o(c / s)} \\
& A_{(c / s) \text { of fin }}=\frac{\pi}{4}\left[\left(2 h_{\text {fin }}\right)+d_{o}\right]^{2} \\
& A_{o(c / s)}=\frac{\pi}{4} d_{o}{ }^{2}
\end{aligned}
$$

$\mathrm{A}_{(\mathrm{c} / \mathrm{s})_{\text {of fin }}}=\quad$ Cross sectional area of fin considering it as circular disc

$\mathrm{A}_{\mathrm{o}(\mathrm{c} / \mathrm{s})}=\quad$ Cross sectional area of inner tube based on outer diameter

The overall heat transfer coefficient based on the outer surface area of inner tube is

$$
\frac{1}{\mathrm{U}}=\frac{1}{\mathrm{~h}_{\mathrm{o}}}+\frac{\mathrm{A}_{\mathrm{o}}}{\mathrm{A}_{\mathrm{i}}} \mathrm{R}_{\text {wall }}+\frac{\mathrm{A}_{\mathrm{o}}}{\mathrm{A}_{\mathrm{i}} \mathrm{h}_{\mathrm{i}}} \quad[3]
$$

Where,

$A_{i}=\quad$ inner surface area of inner tube

$\mathrm{R}_{\mathrm{wall}}=$ thermal resistance of inner tube wall

$$
\begin{aligned}
& A_{i}=\pi d_{i} l \\
& R_{\text {wall }}=\frac{d_{i} \ln \frac{d_{o}}{d_{i}}}{2 K_{t}}
\end{aligned}
$$

By putting the value of $h_{i}$ into equation (16), shell side heat transfer coefficient $h_{o}$ is obtained.

The Nusselt number for the shell side is given by

$$
\mathrm{Nu}=\frac{\mathrm{h}_{\mathrm{o}} \mathrm{d}_{\mathrm{h}}}{\mathrm{K}_{\text {glycerol }}}
$$

Where, $d_{h}=$ hydraulic diameter for the shell side

The shell side can be considered as the helical channel with rectangular cross section [1]. The hydraulic diameter for the rectangular cross section is given as

$$
\begin{aligned}
\mathrm{d}_{\mathrm{h}} & =\frac{4 \mathrm{~h}_{\mathrm{c}} \mathrm{p}}{2\left(\mathrm{~h}_{\mathrm{c}}+\mathrm{p}\right)} \\
\mathrm{h}_{\mathrm{c}} & =\mathrm{h}_{\text {fin }}+\mathrm{c}
\end{aligned}
$$

The Reynolds number and Prandtl number obtained as

$$
\begin{aligned}
& R e=\frac{\rho V d_{h}}{\mu} \\
& P r=\frac{\mu C_{p}}{K}
\end{aligned}
$$

\section{RESULTS AND DISCUSSIONS}

Experiments were conducted to study the effect of following parameters:

I) Variation of flow rate between $200 \mathrm{LPH}$ to $400 \mathrm{LPH}$ for the glycerol and flow rate of water is constant at 750LPH.

II) Variation of speed of rotation of inner tube from 0 RPM to 100 RPM.

The experimental Results are compared with the theoretical results obtained by using Dittus-Boelter Equation which is applied for plain tube in tube heat exchanger. The variation of the Nusselt number with Reynolds number for the stationary inner tube obtained from the experimental results is shown in Fig-3. The Nusselt number obtained for the plain inner tube from the Dittus-Boelter equation and is also plotted in the Fig-3. The graph shows that as Re increases the $\mathrm{Nu}$ increases both for plain tube in tube and for finned inner tube heat exchanger. The Nusselt number obtained with the helical fins on the outer surface of the inner tube is higher than that obtained for the plain inner tube. The Nusselt number with only helical fins are 4 times more than that of plain tube heat exchanger.

The speed of rotation of the inner tube is varied from the 0 $\mathrm{rpm}$ to $100 \mathrm{rpm}$ in the steps of $50 \mathrm{rpm}$. The Nusselt numbers obtained for each speed of rotation are plotted in the Fig-4. The graph shows that as the speed of rotation increases the Nusselt number goes on increasing for the same Reynolds number. The Nusselt numbers at the speed $50 \mathrm{rpm}$ and 100 $\mathrm{rpm}$ are $36 \%$ and $64 \%$ more than that of stationary inner tube. The Nusselt number at $100 \mathrm{rpm}$ is $21 \%$ higher than that of $50 \mathrm{rpm}$.

$\mathrm{K}_{\mathrm{t}}=$ thermal conductivity of inner tube material. 


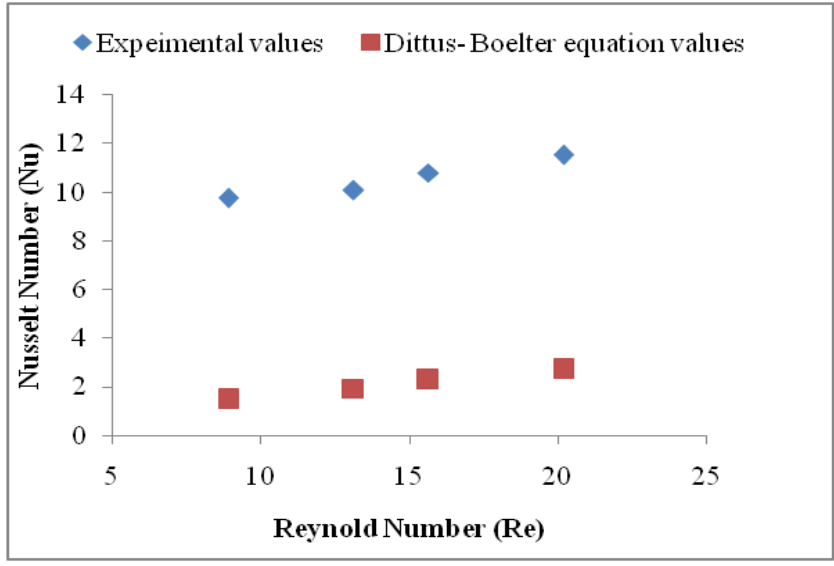

Fig -3: Comparison of experimental results with DittusBoelter equation results for stationary inner tube

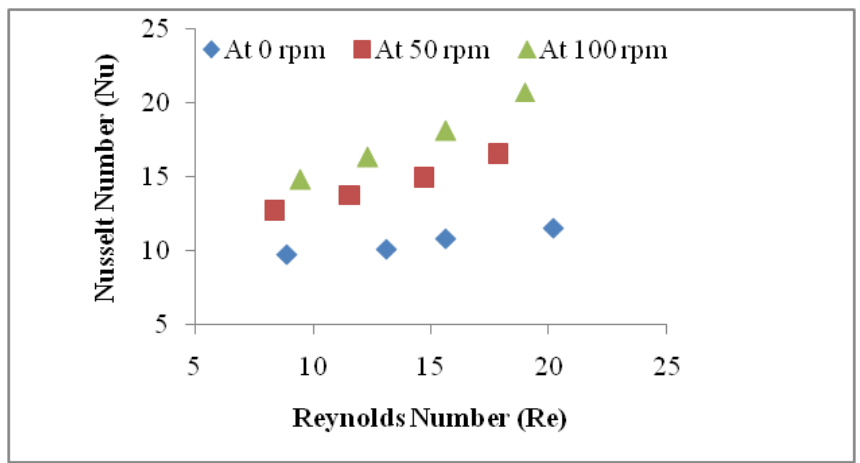

Fig -4: Comparison of experimental results for different speeds

\section{CONCLUSIONS}

The Nusselt number obtained from the experimental results are higher than that of theoretical values obtained from Dittus-Boelter equation. The helical fins over the inner tube results into the increase in the heat transfer area and reduction in the hydraulic diameter of the flow channel. In addition to this the rotation of inner tube enhances the turbulence and mixing of fluid molecules which is necessary to enhance the heat transfer rate in the convection mode of heat transfer. For the present work the Nusselt number for the inner tube with helical fins is 4 times higher than that of the plain inner tube for stationary condition. The Nusselt numbers at the speed $50 \mathrm{rpm}$ and $100 \mathrm{rpm}$ are $36 \%$ and $64 \%$ more than that of stationary inner tube. The Nusselt numbers at $100 \mathrm{rpm}$ are $21 \%$ higher than that of $50 \mathrm{rpm}$.

\section{ACKNOWLEDGEMENTS}

I with great pleasure take this opportunity to express my deep sense of gratitude towards Walchand College of Engineering, Sangli for allowing me to do the dissertation work and all other library and laboratory facilities like heat engine lab available in college. I also would like to thank Assistant Prof. P. A. Mane, Department of Mechanical Engineering for his valuable guidance and constant inspiration during the completion of this paper. I express our special thanks to Prof .Dr .B.S. Gawali, Head of Department of Mechanical Engineering for their guidance whenever necessary. My sincere thanks to all my fellow student friends for their valuable suggestions \& co-operation and constant appreciation and inspiration as well. Lastly, I would like to thank all those who helped me directly or indirectly.

\section{APPENDIX A. NOMENCLATURE}

$h_{o} \quad$ Shell side convective heat transfer coefficient

Q Heat transfer rate

$\dot{m} \quad$ Mass flow rate

$C_{p} \quad$ Specific heat

$\mathrm{T} \quad$ Temperature

$U \quad$ Overall heat transfer coefficient

A Surface area

LMTD Logarithmic mean temperature difference

$A_{o} \quad$ Heat transfer area based on outer diameter of the inner tube and surface area of fins

$d_{o} \quad$ Outer diameter of inner tube

$l \quad$ Total length of fins

$A_{f} \quad$ Surface area of the helical fins

$n \quad$ Number of fins

$A_{\text {fin }} \quad$ Surface area of single fin

$p \quad$ Pitch of the helical fins

$h_{\text {fin }} \quad$ Height of fin

$h_{i} \quad$ Tube side convective heat transfer coefficient

$A_{i} \quad$ Heat transfer area based on the inner diameter of the inner tube

$R_{\text {wall }} \quad$ Thermal resistance of inner tube wall

$d_{i} \quad$ Inner diameter of inner tube

$K_{t} \quad$ Thermal conductivity of inner tube material

$\mathrm{Nu} \quad$ Nusselt number

$d_{h} \quad$ Hydraulic diameter

$h_{c} \quad$ Height of flow channel

$c \quad$ Clearance between fin and inner surface of outer tube

$R_{e} \quad$ Reynolds number

$P_{r} \quad$ Prandtl number

V Velocity

Greek Symbols

$\rho \quad$ Density of fluid

$\mu \quad$ Dynamic viscosity of the fluid

$\theta \quad$ Temperature difference

Subscript

avg Average

o Outer

i Inner

\section{REFERENCES}

[1] Li Zhang, Hongmei Guo, Jianhua Wu, Wenjuan Du, "Compound Heat Transfer Enhancement for Shell Side of Double-Pipe Heat Exchanger by Helical Fins and Vortex Generators", Heat Mass Transfer, Vol. 48, pp 1113 - 1124, 2012.

[2] W. El Maghlany, E. Eid, M. Teamah, L. Shahrour, “ Experimental Study for Double Pipe Heat Exchanger with Rotating Inner Pipe", International Journal of Advanced Scientific and Technical Research, Issue 2 Vol. 4, pp. $507-524,2012$. 
[3] Zhengguo Zhang, Dabin Ma, Xiaoming Fang, Xuenong Gao, "Experimental and Numerical Heat Transfer in a Helically Baffled Heat Exchanger Combined with One Three-Dimensional Finned Tube", Chemical Engineering and Processing, Vol. 47, pp 1738-1743, 2008.

[4] Haifa El-Sadi, Nabil Esmail, Andreas K. Athienitis, "High Viscous Liquids as a Source in Micro-Screw Heat Exchanger: Fabrication, Simulation and Experiments", Microsystem Technologies, Vol. 13, pp 1581-1587, 2007.

[5] M. R. H. Nobari, K. Gharali, "A Numerical Study of Flow and Heat Transfer in Internally Finned Rotating Straight Pipes and Stationary Curved Pipes", International Journal of Heat and Mass Transfer, Vol. 49, pp 1185-1194, 2006.

[6] Pravin Mane, Ashutosh Dasare, Ganesh Deshmukh, Pratik Bhuyar, Kshiteej Deshmukh, Aditya Barve, "Numerical Analysis of Pulse Tube Cryocooler", International Journal of Innovative Research in Science, Engineering and Technology, Vol. 2, Issue 3, pp 591-598, 2013.

[7] Seema S. Vanamane, Pravin A. Mane, "Design, Manufacture and Analysis of Belt Conveyor System used for Cooling of Mould", International Journal of Engineering Research and Applications, Vol. 2, Issue 3, pp.2162-2167, 2012,

[8] S. S. Vanamane, P. A. Mane , K. H. Inamdar, "Design and its Verification of Belt Conveyor System used for Cooling of Mould using Belt Comp Software ", International Journal of Applied Research in Mechanical Engineering, Volume-1, Issue-1, pp 48$52,2011$.

\section{BIOGRAPHIES}

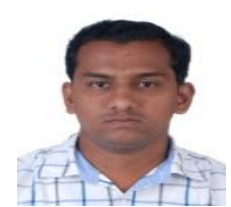

Shewale Omkar M., Department of Mechanical Engineering, Walchand College of Engineering, Sangli, Maharashtra, India

Email id:- omkar7077@gmail.com

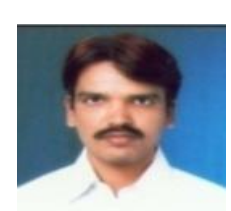

Mane Pravin A., Department of Mechanical Engineering, Walchand College of Engineering, Sangli, Maharashtra, India

Email id:pravin.mane@walchandsangli.ac.in

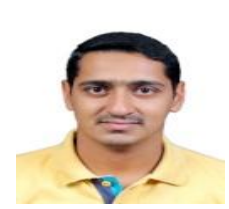

Gazge Sajid A Hameed, Department of Mechanical Engineering, Walchand College of Engineering, Sangli, Maharashtra, India

Email id:- gazgesajid@gmail.com

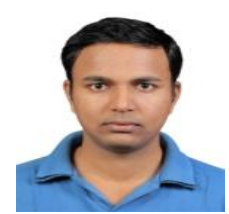

Pasanna Pradeep A., Department of Mechanical Engineering, Walchand College of Engineering, Sangli, Maharashtra, India

Email id: impradeep88@gmail.com 